\title{
O FOLHETIM DA PSICANÁLISE
}

\author{
Marco Antonio Maschio C. Chaga ${ }^{*}$
}

omo disciplina auxiliar da teoria literária, da história e de todo o campo das ciências humanas, a psicanálise desempenhou um importante papel ao longo de toda a existência do Folhetim (1977-1989) da Folha de Säo Paulo. A relevância da atividade psicanalítica pôde ser percebida por, pelo menos, duas formas distintas: o papel interno e o externo articulado pela disciplina. Internamente, a psicanálise acionou uma série de engrenagens que potencializavam a amplitude das análises e interpretações dos mais variados fenômenos sociais e políticos dos anos finais da década de setenta, que se sustentaram ao longo de toda a década seguinte. Externamente, o saber psicanalítico pairava sobre as cabeças dos jornalistas e dos intelectuais que estiveram à frente da editoria do Folhetim, fornecendo subsídios suficientes para que o jargão específico da psicanálise fosse incorporado ao discurso de resistência do final dos anos setenta e início dos oitenta.

Antes de entrarmos no exame específico de alguns desdobramentos que a circulação das idéias advindas da psicanálise tiveram ao longo da existência do Folhetim, gostaria de deixar claro que, para melhor compreender os conjuntos de textos publicados pelo suplemento, tive a necessidade de dividi-lo em três fases distintas. A primeira fase, entre 1977 e 1979, foi um periodo de definição do suplemento, quando ainda não havia sido estabelecido um projeto de atuação global, que pudesse caracterizá-lo como um veículo "sério" e capaz de refletir sobre os

* Universidade Federal do Paraná. Bolsista CNPq/RD. 
problemas nacionais. Enfim, durante esta primeira fase, o Folhetim era um tipo de concorrente do bem humorado Pasquim. A segunda fase do suplemento, entre 1979 e 1982, foi um período extremamente rico para que ocorresse a propagação de uma série de discussões sobre os rumos políticos, sociais, raciais, e o papel da psicanálise foi uma espécie de intervenção, que procurava identificar os reais inimigos da sociedade brasileira. A terceira fase, entre 1983 e 1989, se descolou das discussões políticas e se voltou para o reatamento das ligações entre o jomal e os professores universitários. Nessa época, o tema psicanalítico não deixou de fazer parte do suplemento, porém sua presença foi ligeiramente modificada e seu papel deixou de ser uma das formas de explicação da realidade nacional, passando a se converter em uma espécie de apêndice de várias outras disciplinas.

O problema que procurarei apresentar nas páginas seguintes nasceu de uma pergunta: por que a psicanálise apareceu em circunstâncias que significaram profundas mudanças de direção do suplemento? A trajetória dos textos que construíram o corpus da discussão psicanalítica no Folhetim foi, em grande parte, determinada pela atividade oblíqua desempenhada pelo tema. O papel de obliquiidade encarnado pelas discussões psicanalíticas serviu como ponto de passagem (e também como uma referência) entre a segunda e a terceira fase do suplemento. Inicialmente, poderia justificar a escolha em virtude de seu "funcionamento" ter significado um divisor de águas para o suplemento.

Parece-me, contudo, que o uso da psicanálise, por parte do Folhetim, sugere algum tipo de reconhecimento terapêutico e curativo atribuído a esta prática clínica. No número 140, o Folhetim publicava o primeiro conjunto de textos dedicados exclusivamente à psicanálise. Reportagens sobre o pequeno interesse de Freud em relação às causas feministas; entrevista com o primeiro psicanalista paulista, Durval Marcondes; glossários explicativos contendo os principais termos freudianos; informações sobre as técnicas freudianas; noções gerais sobre a atividade da análise; apresentação de notas biográficas sobre a vida de Freud e para encerrar o número, um ensaio introdutório sobre Jacques Lacan, que arrolava as principais consequiências de sua contribuição à psicanálise contemporânea.

Diante daquilo que viria a ser uma das grandes séries publicadas pelo suplemento, gostaria de propor três hipóteses de leitura a respeito da circulação das idéias psicanalíticas no Folhetim. Porém, antes de apresentar estas hipóteses, preciso indicar alguns roteiros percorridos pela série psiquiatria e psicologia que, por definição, são disciplinas que tangenciam as questões psicanalíticas e, muitas vezes, causam uma certa confusão entre os termos. 


\section{Antecedentes}

Antes do suplemento optar pela psicanálise como método para enfrentar os dilemas do nosso passado recente, $o$ Folhetim, procurando discutir questões pontuais, havia aberto o espaço à psiquiatria e à psicologia.

Em relação ao debate psiquiátrico, ${ }^{1}$ o principal foco de interesse girava em torno de dois problemas: a dependência química das drogas e os métodos medievais utilizados nos hospitais psiquiátricos. Conseqüentemente, os textos se centralizavam sobre a necessidade de pensar em alternativas mais humanas para se tratar a loucura de forma ambulatorial, e, no caso da dependência química, a discussão sobre a descriminalização dos usuários e as alternativas aos métodos tradicionais de privação da liberdade ganhavam força. ${ }^{2}$

Caso admitamos que os textos que discutem a psicanálise são de domínio da psicologia, não podemos, sob pena de confundirmos os domínios, permitir que o juizo contrário seja admitido. Sendo assim, nem todos os textos que discutem os métodos da psicologia comportamental, pré ou pós Freud, podem ser confundidos com os domínios da psicanálise. Uma disciplina pode ser dependente da outra, mas isso não quer dizer que se deva sobrepor a análise (decorrente da prática psicanalítica) às diversas terapias e psicoterapias (decorrentes das diversas práticas da psicologia

1 Como sabemos, para ser psiquiatra é necessário ter formação médica. Além disso, a psiquiatria se difere da psicologia e da psicanálise por abordar a mente humana de um ponto de vista exclusivamente bioquímico. Sendo assim, contrária a muitas práticas "obscuras" dos psicólogos e dos psicanalistas, os psiquiatras apostam na "cura" de seus pacientes através da prescrição de drogas, que visam a complementar certas deficiências psíquicas. Essa prática é condenada por boa parte dos psicanalistas e psicólogos, pois eles acreditam que os métodos psicoterapêuticos e a análise, respectivamente, podem oferecer melhores resultados sem causar nenhum tipo de dependência química, minimizando assim os efeitos da "cura". Já a distinção entre psicanálise e psicologia é mais complexa, mas pode ser resumida através de seus métodos. Genericamente, o "tratamento" psicológico visa a uma mudança comportamental. A "cura", nesse caso, obedece outra lógica. Trata-se de detectar um comportamento social "inadequado", para, através das terapias, redirecionar esse indivíduo ao convívio social "adequado". Se for possível reconhecer um método na psicologia, a psicanálise, por sua vez, questiona a própria noçāo de "método" e de "cura". Há um método, mas ele se baseia em regras que não são fixas (as associaçōes livres), variando de acordo com o "caso". Fundamentalmente, a psicanálise se difere da psicologia e da psiquiatria por não tratar o inconsciente munido de alguma lógica apriorística. "Mas o inconsciente tal qual Freud o detectou, o inconsciente estruturado como um 'rébus', um enigma, um discurso puramente significante, isto $e$, como 'uma linguagem'. [Contudo] a psicanálise não é uma gramática, língua ou lingüística, ela é fala". In: CHECHINATO, D. Psicanálise e poder dominante, n. 308. Folha de São Paulo, 12 dez. 1982, Folhetim, p. 3.

2 Ver anexo I. 
comportamental). Esta distinção é fundamental para se entender a proliferação difusa dos textos que trataram da psicologia. Esse conjunto de textos não chegou a formar um núcleo direcionado a este ou àquele problema específico, como se percebeu anteriormente na série dedicada à psiquiatria, porque a psicologia sofreu, por parte dos jornalistas, uma série de relativizações e usos superficiais que alimentaram uma certa panacéia interpretativa sobre a disciplina. ${ }^{3}$

Contudo, há uma entrevista, "O divã da periferia”, com o psicólogo Jacob Pinheiro Goldenberg, que pode servir como uma passagem que, a seguir, fecharia o foco sobre questões exclusivas ao campo da psicanálise. Nessa entrevista, Jacob Pinheiro Goldenberg defende a idéia de se "levar o divã" às regiōes periféricas das grandes cidades, através da igreja, sindicatos e associações de bairro. A jornalista Sônia Regina Nabarrete salientava, no início da entrevista, que "o Brasil precisa deitar no divã e falar de suas angústias. Mas como conseguir isso se a psicoterapia é um privilégio de classes abastadas e grande parte da população ganha salário mínimo (...)". ${ }^{4}$ Esta entrevista é crucial, porque coloca na ordem do dia a questão, que se aprofundaria posteriormente, entre a perspectiva individualista e coletivista da psicanálise.

Sem dúvida, parece que o discurso psicanalítico teve lugar nodal dentro das séries que sustentaram o suplemento, não somente pela discussão das implicações contemporâneas das descobertas e invenções da psicanálise, mas, sobretudo, porque estes textos estão instalados em pontos estratégicos dentro da "história" do Folhetim. O uso da psicanálise como metáfora que objetiva "curar" os males políticos do país desliza e toma outros rumos, servindo inclusive para explicitar outras preocupações próximas, como a do feminismo, a da homossexualidade, ou o questionamento da ontologia, por exemplo.

Porém, antes de observarmos essas "aplicações" da teoria freudiana, vale lembrar que a instituição psicanalítica passou por uma "revisão" interna, que procurou discutir quais eram de fato as implicações políticas da instituição: ou a psicanálise era tributária do individualismo e, conseqüentemente, se destinava a uma fração burguesa da sociedade ou suas atribuições sociais se pautavam pelo reconhecimento do coletivo e, por conseguinte, os profissionais da área estavam aptos para reconhecer a relevância e o papel social da psicanálise.

3 Ver anexo II.

4 GOLDENBERG, J. P. O divã da periferia. Folhetim, n. 112, 11 mar. 1979. Folha de São Paulo, p. 8. Entrevista concedida a Sonia Nabarrete. 


\section{A psicanálise e o psicanalista}

O itinerário da "cura nacional" foi-se descortinando enquanto me deparava com os textos que constituíam a série "psicanálise". A chave para se começar a entender a sina destinada à psicanálise no Folhetim teve início quando foi publicado o n. 140. A partir dele, pude estabelecer um eixo que fosse capaz de evidenciar os dois principais usos que o termo teria ao longo dos anos oitenta.

Hipótese histórica: em 23 de setembro de 1979, a psicanálise pôde ser veiculada como um sinal de que a independência tardia da imprensa frente à ditadura tinha sido consolidada. Apressando o movimento do calendário, o $\mathrm{n}$. 140 representou o fim da década de setenta e a abertura dos anos oitenta. Comemorávamos, com esta publicação, a democratização da rotina dos brasileiros e parecia mesmo ser necessária a utilização de um método científico, mas ao mesmo tempo obscuro e quase místico, para zerar a memória associada aos acontecimentos mais recentes da vida nacional. Para o movimento psicanalítico brasileiro, o período também significou a politização da discussão, quando a "psicanálise de esquerda" pôde se manifestar e evidenciar o predomínio do autoritarismo da "direita", decorrente dos anos da ditadura. O número seguinte, - 141, complementava a estratégia iniciada na semana anterior, já que estreava a publicação, na penúltima página do suplemento, de um balanço que fornecia, ano a ano, os principais acontecimentos políticos e culturais dos anos setenta. Batizada de "Jornal da década", informativa, mas sem opinião, esta seção oferecia uma série de fragmentos, que funcionavam como uma mini e leve história da repressão e da censura no Brasil. Todas essas modificações, embora fossem simples, indicavam que a década estava fechando para balanço. Por um lado, isso era motivo suficiente para se comemorar, já que, àquela altura dos acontecimentos, se apostava alto em um futuro democrático capaz de equalizar grande parte dos problemas sociais. Contudo, em outra perspectiva, a década de setenta tinha um significado sinistro, que, por diversas razões políticas e sobretudo históricas, deveria ser silenciado.

Para o Folhetim, a série psiquiátrica e os textos sobre psicologia tinham exaurido suas forças logo no início dos anos oitenta e todas as atenções se voltavam para os usos da psicanálise. Inicialmente, no limiar da década de setenta, procurouse discutir a validade e a amplitude social da prática freudiana. Diante da falta de resultados concretos sobre a capacidade de a psicanálise atingir uma gama maior da população, procurou-se ressaltar as conquistas individuais. Em março de 1981, Irene 
Ravache, Enio Mainardi e Carlito Maia $^{5}$ atestavam, através de pequenos depoimentos, os resultados positivos advindos da experiência psicanalítica. Durante uma época em que o pensamento de esquerda desconfiava das atividades que não tivessem um compromisso claro com a consolidação das conquistas democráticas, a psicanálise passou a sofrer ataques constantes, que a vinculavam ao autoritarismo político e ao individualismo. $\mathrm{O}$ assunto que se tinha iniciado com a entrevista de Jacob Pinheiro Goldenberg, citada anteriormente, retornava com frequiência às páginas do suplemento. Mas, é preciso entender que os ataques desferidos à psicanálise tinham dois endereços: no primeiro caso, era mesmo uma estreita visão da disciplina que, padecendo pela falta de compreensão da matéria, exigia da psicanálise e do psicanalista uma postura política voltada à solução dos problemas coletivos do país; ${ }^{6}$ em outro plano, entretanto, as páginas do suplemento serviram de abrigo à exposição de uma crise gerada no interior da Sociedade Psicanalítica do Rio de Janeiro, que se alastraria por outros institutos psicanalíticos do país (devo acrescentar que a polêmica envolvendo membros da SPRJ foi a mais longa polêmica acompanhada pelo suplemento).

Resumidamente, a crise surgiu depois que um grupo de psicanalistas, liderados por Eduardo Mascarenhas e Hélio Pellegrino, criaram, no início dos anos

5 "Depoimentos". Folha de São Paulo, 8 mar. 1981. p. 11. Depoimentos de Irene Ravache, Enio Mainardi e Carlito Maia. Folhetim, n. 217.

6 Terry Eagleton reconhecia, em 1983, que a psicanálise padecia deste mal em âmbito mundi-

al.

Uma crítica a Freud por vezes ainda ouvida na Esquerda política é a de que seu pensamento é individualista - que ele coloca causas e explicações psicológicas 'particulares' em lugar das sociais e históricas. Tal acusação reflete uma incomprecnsão radical da tcoria freudiana. De fato existe um problema real em relação à maneira pela qual os fatores sociais e históricos se relacionam com o inconsciente; um dos objetivos da obra de Freud, porém, é tomar possivel pensarmos o desenvolvimento do indivíduo humano $\mathrm{cm}$ termos sociais $\mathrm{c}$ históricos. O que Freud produz, na verdade, nada menos é do que uma tcoria materialista da criaçāo do sujeito humano. Chegamos a ser o que somos por uma inter-relação de corpos - pelas complexas transaçōes que ocorrem durante a infäncia entre nossos corpos $\mathrm{c}$ aqueles que nos cercam. Isso não é reducionismo biológico: Freud decerto não acredita que scjamos apenas os nossos corpos, ou que nossas mentes sejam simples reflexos deles. Nem constitui a sua tcoria um modelo a-social da vida, já que os corpos que nos cercam, $\mathbf{e}$ nossas relações com eles, são sempre socialmente específicos. Os papéis dos pais, as práticas do cuidado com a criança, as imagens e crenças associadas a tudo isso são aspectos culturais que podem variar consideravelmente de uma sociedade para outra, ou de um momento histórico para outro. A infância ć uma invenção histórica recente, $c$ a gama de diferentes cenários históricos abrangida pela palavra familia dá-lhe um valor limitado. Uma crença que aparentemente não variou nessas instituiçōes é a suposição de que as meninas $\mathrm{c}$ as mulheres são inferiores aos meninos $\mathrm{e}$ aos homens: tal preconccito parece aproximar todas as sociedades conhecidas. Como se trata de um preconceito com raízes profundas em nosso desenvolvimento sexual e familiar inicial, a psicanálise ganhou grande importância para algumas feministas. EAGLETON, T. Teoria da literatura: uma introdução, p. 176-177. 
oitenta, o "Fórum de Debates", entidade que deveria lutar pela popularização da psicanálise, retirando-a de seu panteão dourado; também havia uma denúncia de que Amílcar Lobo (posteriormente desligado da Sociedade), então psicanalista associado à SPRJ, fora torturador durante o governo de Médici. Todavia, o diretor da SPRJ, Vitor Manuel de Andrade, decidiu expulsar os criadores do "Fórum de Debates", porque via nessa Instituição, não apenas um movimento de oposição, mas a criação de um verdadeiro poder paralelo dentro da Instituição.?

Contrário ao "Fórum de Debates", porém, por outros motivos, também se encontrava Chaim Samuel Katz, que se irritava com o fato de Eduardo Mascarenhas estar conquistando consagração nos meios televisivos, às custas daquilo que Chaim chamou de "conduta de sexólogo", promovendo o detrimento da "verdadeira" psicanálise com bases científicas. ${ }^{8}$

Procurando se distanciar tanto da versão televisiva da "sexologia" de Eduardo Mascarenhas, quanto da irritação de Chaim Samuel Katz, em defesa da "ciência" psicanalítica, Maria Rita Kehl reconhecia que os anos de ditadura haviam disseminado entre nós uma profunda falta de traquejo para se lidar com os mecanismos democráticos. "A censura e a repressão dos últimos quinze anos nos fizeram muito mais mal do que se calcula: hoje, tentando recuperar o hábito do debate e da livre troca e formação de opiniões, estamos meio perdidos em relação ao que interessa discutir". 9

O que interessava ser discutido era, sobretudo, o papel da psicanálise à época, debate este embaçado por discussões paralelas que não despertavam o interesse do público, nem dos especialistas.

Só a socialização da práxis psicanalítica pode dessacralizar esta ciência-mito dos nossos dias, que, apesar de tudo nem sabemos direito se é ciência ou não (o que a meu ver não desautoriza a

7 Um dos desdobramentos políticos dessa crise se tornaria mais claro a partir do Folhetim $\mathbf{n}$. 280, 30 de maio de 1982, quando Chaim Samuel Katz, saindo em defesa da SPRJ ou da psicanálise de direita, passaria a questionar a utilização da disciplina como ponta de lança da esquerda, enfatizando que, caso se quisesse reconhecer algum valor na democracia, ele deveria servir, necessariamente, para os dois lados. Essas críticas eram endereçadas ao lbrapsi (Instituto Brasileiro de Psicanálise) que, três números mais tarde (n. 283, de 20 de junho de 1982), daria continuidade à polêmica.

8 Alguns dos principais desdobramentos dessa crise podem ser encontrados no Folhetim $\mathrm{n}$. 254, de 29 de novembro de 1981. Contudo, como a listagem dos textos apresentada anteriormente demonstra, a polêmica seria ainda protelada por vários meses.

9 KEHL, M. R. O mito do psicanalista. Folha de São Paulo, 29 nov. 1981. Folhetim, n. 254, p.

9. 
psicanálise). Somente se, enquanto prática - e não apenas enquanto tema de papo, onde os iniciados dão as coordenadas para a massa - a psicanálise cair na vida, a exemplo do que ocorreu em alguns países europeus, como Itália e França, revelando suas limitações enquanto disciplina social e ampliando suas possibilidades, poderá deixar de ser um Saber Sagrado para milhões de invejosos e se constituir em algum tipo de conhecimento de domínio e utilidade pública. ${ }^{10}$

O desenvolvimento dos acontecimentos, ao longo dos anos oitenta, demonstrou que a disciplina psicanalítica cairia na vida, passando a desempenhar um papel decisivo, embora coadjuvante, em análises literárias, históricas, sociológicas, econômicas. Talvez essa guinada da psicanálise não correspondesse aos desejos presentes no fragmento citado anteriormente, mas seus usos não seriam em vão. A psicanálise serviria e auxiliaria muitas outras disciplinas a se reconhecerem em uma época que, cada vez mais, se tornava imprecisa, e a dificuldade de formular novas conceituações se mostrava mais presente. Seja como for, a transposição dos limites das quatro paredes, comuns à prática da psicanálise, foi superada e a disciplina passaria a se consolidar entre diversas "falas": a fala da história, a discursividade da literatura, a desrrepressão das minorias.

No Folhetim, os psicanalistas tiveram uma trajetória que se assemelha àquela verificada anteriormente pelos jornalistas. Inicialmente, entre 1979 e 1982, os psicanalistas puderam escrever, com exclusividade, ocupando este espaço para, além das polêmicas, divulgar interpretações sobre alguns fenômenos contemporâneos que necessitavam de uma perspectiva diferente das usuais. Assim, a psicanálise havia se prestado à interpretação tanto do papel das novelas televisivas no imaginário popular, quanto tinha servido para a análise do pacto social e a conseqüente democratização da sociedade brasileira. Além disso, percebemos a preocupação em analisar a explosão demográfica da cidade de São Paulo, bem como se estuda o aumento da violência em nosso cotidiano. Estes foram alguns dos temas enfocados; portanto, não é por acaso que, com ligeiros deslocamentos, os textos dos principais colaboradores (dos especialistas) psicanalistas obedecem a uma trajetória específica: primeiro aparecem os textos ligados às polêmicas, depois as preocupações políticas, finalmente, reflete-se sobre alguma especificidade da época e, às vezes, os 
"especialistas" se transformam em escritores e poetas. ${ }^{11}$ Nesse sentido, vale indicar que, depois de 1983, observamos o declínio da colaboração dos especialistas, que esteve concentrada nos primeiros anos da década de oitenta.

\section{A psicanálise a serviço das ciências humanas}

Hipótese teórica: até o número 139 , fez parte da rotina do suplemento a publicação de crônicas e ficção; depois do número 140 , o Folhetim passou a se comprometer de forma mais enfática com os destinos da cidadania, promovendo os célebres debates sobre os rumos da "Sociedade Civil", que tinha representado (antes da revoada dos professores universitários) a época de ouro do suplemento, período no qual "o Folhetim era compreensível". Abrindo a década de oitenta, a psicanálise se apresentava e foi, sob diversas formas, reconhecida como um método, ou como uma disciplina, dotada de poderes extremos para fornecer saídas e resolver impasses existentes no interior das ciências humanas. A panacéia criada em torno da psicanálise como resposta às discussões do nacional também se estendeu para o campo das ciências humanas criando uma expectativa que, como veremos, não se converteu em soluções duradouras.

Havia uma crise, cujo principal sintoma pode ser creditado ao ensaísmo reinante durante a década de oitenta e, para agravar ainda mais essa crise, ocorria um certo declínio e questionamento das sínteses dialéticas. Nesta época, a invenção de Freud ganhava potencializações (via Jacques Lacan, por exemplo) e, com estes desdobramentos, as certezas oriundas dos sistemas cartesianos passaram a receber mais alguns golpes.

Devo acrescentar ainda que, a partir de 1983, a idéia de utilizar a psicanálise como um modelo explicativo de toda a panacéia de questões que surgiam com nova vitalidade depois da abertura democrática, vai sendo abandonada pelos interlocutores e protagonistas das polêmicas psicanalíticas. Sendo assim, ao sucumbir diante do desafio de colocar o país no divã, a disciplina passa a desempenhar outros papéis não menos importantes, mas seguramente menos infrutíferos - dentro do suplemento.

Assim, a partir deste período, os textos que tratam do tema podem ser relacionados a outras disciplinas e a presença dos "especialistas" em psicanálise passa a conviver, gradativamente, com usos interdisciplinares do termo, cedendo

11 Ver anexo III. 
espaço para outros profissionais, principalmente os professores universitários, "especularem" sobre o tema. A partir de meados dos anos oitenta, a associação entre a psicanálise e a literatura (embora se perceba, com menor intensidade, outras relações com a história, a sociologia e a filosofia) se tornam parte da rotina do suplemento, retornando à baila (com exceção de 1986) ano a ano. ${ }^{12}$

\section{Dois exemplos}

Procurando superar a fronteira entre a psicanálise e a filosofia, ao mesmo tempo em que enfatizava a necessidade desse diálogo, Zeljko Loparic observava que a disciplina freudiana dialoga com melhor fluência com sistemas filosóficos que são assistemáticos (de Nietzsche, por exemplo), ou são extremamente críticos em relação à crença excessiva nesses sistemas (Kant e Heidegger).

Poder-se-ia então falar em um Freud racionalista? Sem dúvida, desde que se entenda que o seu racionalismo era essencialmente

12 A seguir, apresento a relação dos "ensaios-literatura" que trazem a palavra-chave "psicanálise" associada.

GAMBOA, G. Uma viagem por Anais Nin. Folha de São Paulo, 1 maio 1983. Folhetim, n. 328. p. 10-11.

GONZÁLEZ, H. Werther e a seduçāo do suicídio. Folha de São Paulo, 31 jul. 1983. Folhetim, n. 341. p. 10-11.

SUSSEKIND, F. Friedrich Schlegel - O chiste e suas relaçōes com o Romantismo. Folha de São Paulo, 14 ago. 1983. Folhetim, n. 343. p. 6-7.

MENEZES, A. B. Literatura e psicanálise. Folha de Säo Paulo, 11 dez. 1983, Folhetim, n. 360. p. 4-5.

SUSSEKIND, F. Ego-trip. Folha de São Paulo, 6 maio 1984. Folhetim n. 381. p. 9-11.

9-11.

MENEZES, A. B. A alquimia da pedra. Folha de São Paulo, 11 nov. 1984. Folhetim. n. 408. p.

POMMER, M. E. Borges e Lacan, Folha de São Paulo, n. 408, 11 nov. 1984. Folhetim. p. 6-8. tim. n. 408. p. 2-3.

WILLEMART, P. Além da psicanálise, a literatura. Folha de São Paulo, 11 nov. 1984. Folhe431. p. 8-9.

FRANCESCHI, A. Assassinato: modo de usar. Folha de Säo Paulo, 21 abr. 1985. Folhetim. n.

RIBEIRO, R. J. O teatro do grande sedutor. Folha de São Paulo, 29 maio 1987. Folhetim. n. 538. p. 6-8.

KOSSOVITCH, E. Os cúmplices da sedução. Folha de São Paulo, 29 maio 1987. Folhetim. n. 538. p. 4-5.

WILLEMART, P. O que procura D. Juan? Folha de São Paulo, 29 maio 1987. Folhetim. n. 538. p. 2-3. 
crítico. Nada revela melhor a postura de Freud do que a sua insistência sobre o que chama de critério de consciência. A consciência é como a vida: não vale muita coisa, diz ele na Lição 31. No entanto é a única coisa de que dispomos para nos guiar na obscuridade da nossa vida mental. Ou seja, a sorte da psicanálise como ciência se decide exatamente no mesmo lugar em que os filósofos desde sempre decidiram entre o verdadeiro e o falso: o campo da consciência. ${ }^{13}$

Auxiliada em larga medida pelas idéias psicanalíticas, as ciências humanas passam a questionar de forma mais incisiva os paradigmas, as tradições, a ontologia, os sistemas baseados na referencialidade, abalando uma série de verdades até então canônicas. Portanto, para além do maniqueísmo de uma ciência (que deveria tanto decidir sobre os eventuais benefícios da verdade, quanto escapar dos malefícios da falsidade), a associação entre literatura e filosofia também ocorre neste espaço da consciência, embora a máxima descartiana - "penso, logo existo" (que coroa a enfática presença da consciência do pensar) - deva ser deslocada para outra equação, não menos lógica do que a anterior, oriunda da seara psicanalítica: "penso onde não existo e existo onde não penso", ou seja, penso fora, na linguagem, e existo dentro de um "corpo" dotado de alguma coisa artificial chamada linguagem. Nesse caso, assumindo esse ônus da "artificialidade", a psicanálise passa a se constituir a partir da grande proximidade entre os psicanalistas e a literatura; de certa forma, a psicanálise passa a depender da literatura.

Todavia, a única vez em que a formulação da correlação entre a literatura e a psicanálise aparece sistematizada no Folhetim, a esperança criada em torno de uma composição sofisticada entre as duas disciplinas não corresponde às expectativas.

Vista do ângulo da literatura, a psicanálise será encarada como um instrumento de leitura do texto literário, exercendo, no processo interpretativo, um papel revelador e desmascarador. No entanto, essa busca de sentido que toda interpretação implica se configurará menos como uma tradução do que como uma

13 LOPARIC, Z. Uma leitura filosófica de Freud. Folha de São Paulo, 31 ago. 1986, Folhetim, n. 499. p. 7. 
construção do sentido do texto. Não se trata tanto de, através da psicanálise, explicar cabalmente uma obra, mas de colocar em evidência uma ou outra de suas condições necessárias. No entanto, importa atenção quanto ao caráter redutor da eventual utilização de um único instrumental analítico. $O$ texto literário é, inescapavelmente, um produto social, necessitando portanto, para ser interpretado, ser situado sobre um chão histórico. Assim, Sociologia da Literatura, Antropologia, História, Lingüística, deveriam concorrer para dar conta (sem esgotá-lo...) de sua explicação. ${ }^{14}$

Concluimos pela necessidade de se fomentar a interdisciplinariedade entre a psicanálise e a literatura, mas o uso da psicanálise é apenas discreto, servindo mais para realçar alguma leitura especificamente literária, funcionando como um apêndice de leitura a mais (da sociologia da literatura, por exemplo). A expectativa e talvez a ansiedade de um uso da psicanálise, que servisse como um discurso capaz de "atravessar" o campo das ciências humanas, seria retardado por alguns anos ainda. O volume da contribuição que envolve a psicanálise no suplemento ${ }^{15}$ comprova que a iniciativa de levar ao público esses textos, que anunciavam novos usos da disciplina, havia emplacado, mas seria ainda necessário mais algum tempo para que esses resultados se transformassem em um "avanço" substancial da reflexão sobre o multiculturalismo.

Em outras palavras, ao invés da utilização do escopo discursivo da psicanálise poder significar a quebra de uma longa série de interpretações fundamentadas em matizes que expressam um uso sistemático da dialética (que repousam na compreensão da tensão existente entre o passado e o presente, visando, assim, a discussão e a implementação de um projeto capaz de solucionar o futuro), o uso específico da disciplina como "instrumento de leitura do texto literário", dependente da história ou da sociologia, implicava o reconhecimento de que a psicanálise padecia de recaídas individualistas, sendo tanto incapaz de ler o nacional, quanto pouco eficaz para se ler o coletivo, embora servisse para auxiliar a leitura do literário.

14 MENESES, A. B. Literatura e Psicanálise. Folha de Säo Paulo, 11 dez. 1983. Folhetim, n. 360. p. 4. Grifos da autora.

15 As dez palavras-chave mais utilizadas durante a indexação do Folhetim (1977-1989) foram as seguintes: Brasil, política, literatura, comportamento, cultura, cinema, poesia, teoria literária, psicanálise e humor. 
Terry Eagleton chama a atenção para os usos mais comuns da psicanálise como disciplina auxiliar das análises literárias. A citação nos interessa, porque além de esclarecer algumas interpretações que encontrei no suplemento, o texto de Eagleton não traz um olhar retrospectivo, já que foi escrito na mesma época (1983) em que essas análises estavam sendo publicadas.

Em linhas gerais, podemos dividir a crítica literária psicanalítica em quatro tipos, dependendo daquilo que ela toma por objeto de atenção. Ela pode se voltar para o autor da obra; para o conteúdo, para a construção formal, ou para o leitor. A maior parte da crítica psicanalítica tem sido dos dois primeiros tipos, que de fato são os mais limitados e problemáticos. A análise psicanalítica do autor é um trabalho especulativo que enfrenta os mesmos tipos de problemas que examinamos ao discutirmos a relevância da "intenção" do autor para as obras literárias. A psicanálise do "conteúdo" - comentários sobre as motivações inconscientes das personagens, ou sobre a significação psicanalítica de objetos ou acontecimentos do texto - tem um valor limitado, mas à semelhança da notória caça ao símbolo fálico, é com muita frequiência redutiva. As investidas esporádicas do próprio Freud no campo da arte e da literatura se fizeram principalmente nesses dois níveis. Ele escreveu uma fascinante monografia sobre Leonardo da Vinci, um ensaio sobre a estátua "Moisés", de Michelangelo, e algumas análises literárias, notadamente sobre um pequeno romance do autor alemão Wilhelm Jensen, intitulado Gradiva. Esses ensaios ou oferecem uma explicação psicanalítica do próprio autor, tal como ele se revela em sua obra, ou examinam sintomas do inconsciente na arte, tal como o fariamos na vida. Em ambos os casos, a "materialidade" do próprio artefato, sua constituição formal específica, tende a passar despercebida. ${ }^{16}$

Depois de detectarmos a forte influência que a literatura teve para o processo de constituição da psicanálise freudiana, todo o jogo literário adquire, através das transgressões associadas aos usos da linguagem, uma nova dimensão, e o campo psicanalítico pode ser re-significado. Assim, percebemos a importância que a disciplina freudiana poderia acrescentar às análises da literatura e das ciências

16 EAGLETON, T. Teoria da literatura: uma introdução. Tradução: Waltensir Dutra. São Paulo: Martins Fontes, 1983. p. 192-193. 
humanas em geral, porém os primeiros ensaios a se permitirem semelhantes aventuras hoje parecem desarticulados e pouco significativos de uma aliança que pretendia muito, mas pouco ofereceu.

\section{Uma versão local do culturalismo}

A terceira hipótese de leitura do fenômeno psicanalítico no Folhetim não possui uma relação direta entre o que era escrito e a teoria. Não devemos perder de vista que o arsenal psicanalítico seria acionado de uma outra forma distinta das anteriores. De maneira difusa (aliás, os deslizamentos metafóricos são uma das principais marcas da atividade psicanalítica), podemos perceber que o uso indireto da psicanálise talvez seja ainda mais relevante do que uma possível intervenção direta do especialista ou da tentativa de adicionar (ainda que a idéia fosse interessante) a psicanálise à outra disciplina. Refiro-me às discussões (através dos debates e reportagens) que trouxeram à tona a questão das minorias. Essas reflexões surgiram nas páginas do suplemento através das contendas sobre o novo papel da mulher (na cultura, na literatura, no casamento, na política) e o direito à cidadania do homossexual, do negro e do índio. Esses debates forçavam a abertura de novos flancos de atuação crítica advindos, principalmente, dos setores mais organizados da sociedade. Assim, fornecia-se, regularmente, munição ao imenso fórum em que se havia transformado o suplemento durante sua segunda fase. ${ }^{17}$ Prova disso é que as palavras-chave mulher, feminismo, racismo e homossexualidade foram empregadas com certa frequiência durante esse período. Esse aspecto também chama a atenção, porque coloca no mesmo plano de preocupações os temas políticos, culturais, econômicos ou a crise do petróleo, ao lado da problemática inserção das minorias no quadro geral da sociedade civil.

Se nas duas hipóteses anteriores havia teoria em excesso e o resultado era quase pífio, nesse terceiro caso, a falta de teoria enfraqueceu em muito o debate. $\mathrm{Na}$ maioria das vezes, estas discussões eram formuladas a partir da experiência acumulada dos convidados; desse modo, acertava-se no alvo dos temas quando se buscava discutir as condições de alteridade dos sujeitos marginalizados por grande parte da sociedade organizada, porém, o resultado final deixava a desejar e, infelizmente, apressava-se o fim dos debates, porque, na maioria dos casos, ao invés

17 Ver anexo IV. 
do aprofundamento dos temas por parte da universidade e dos jornais, a televisão assumiria as discussões (relativizando-as ao máximo), provocando um esgotamento precoce desse "filão" associado aos "marginalizados". Embora a metafísica da presença (o relato individual) seja $a$ marca dessas discussões e a falta de bibliografia prejudique desdobramentos que se aventurassem pelos campos "desconhecidos" da seara cultural e psicanalítica (debate este que será retomado mais tarde pelos estudos culturais), pelo menos, eles deixaram indicações claras e diversas pistas sobre as discussões que marcam o fim deste século, ou seja, os debates enfatizavam a necessidade da quebra das tradições e dos cânones cristalizados, pois somente assim se abririam novos espaços de atuação, forçando a prioridade de se reconhecer como legítimas as reivindicações dos grupos apartados por séculos de uma história abalizada pela dominação social, sexual, racial, econômica e política (aqui talvez seja interessante acrescentar a grande cobertura oferecida, pelo suplemento, ao ascendente fenômeno dos sindicatos).

Desse modo, podemos perceber que o traço de um primeiro rascunho da versão local do culturalismo ganhava uma dinâmica própria; alargava-se no horizonte a possibilidade de transformar toda a discussão em torno das minorias em uma questão nacional e, sobretudo, criava-se a expectativa de se formular, como forma de resposta à política oficial, uma variante capaz de traduzir-se em um multiculturalismo com força suficiente para abarcar e dirimir os dilemas das minorias sociais, raciais, sexuais.

Durante a passagem da década de setenta aos anos oitenta, associar a discussão dos direitos sociais das minorias ao clima da re-democratização política do país era praticamente inevitável, e essa operação aumentava ainda mais a indignação pela falta de uma política federal clara sobre o assunto. Porém, se, como vimos na primeira parte deste trabalho, o descaso do governo era claro em relação à educação, a omissão às reivindicações das minorias esbarrava em um silêncio ainda maior. Aguinaldo Silva resumia esta sequiência de descasos da seguinte forma:

O homossexualismo é nossa culpa. Ele é quem provoca os crimes que os homens condenam. E os que não sabem são, muitas vezes, nossos irmãos. Os negros condenados pela cor, os judeus pela ambição: negros e judeus vendo em nós a imagem do demônio que eles compõem. A eles tinhas de informar, Davi, sou homossexual e sendo, também sou negro e judeu. ${ }^{18}$

18 SILVA, A. Primeira carta aos andróginos. Folha de São Paulo, 30 set. 1979. Folhetim, n. 141. p. 9. Trecho. 
Para compreender melhor a preocupação expressa no fragmento anterior, talvez devêssemos acrescentar: também sou negro, mulher, índio e negro. Sendo assim, percebemos que as questões sociais e políticas estavam coladas umas às outras. Vejamos, por exemplo, como o suplemento abria o debate sobre as conquistas das mulheres nos anos setenta:

Se na década de 60, em sua marcha pela libertação sexual e pela igualdade de direitos, a mulher teve gestos simbólicos, como a famosa "queima de sutiãs", nos anos 70 tais gestos foram substituídos por uma ação mais direta e organizada, alterando a legislação em muitos países, atacando os valores esclerosados da sociedade patriarcal e dando um novo rumo a todo o processo social. No Brasil, a violência - tanto da repressão policial quanto do arrocho econômico - levou-a a levantar a cabeça e assumir papéis fundamentais no quadro da mobilização social, sem ignorar seus problemas especificos. ${ }^{19}$

Essa terceira hipótese de leitura permite que se perceba a proximidade entre o universo psicanalítico e o "quadro da mobilização social", pois ela é favorecida por dois movimentos diferentes, mas complementares. Em primeiro lugar, é possível perceber que a queda do nome do pai questiona a norma (na medida em que o conjunto das leis é questionado ou modificado); por outro lado, a recorrente resignificação dos "gestos simbólicos" do passado traz um passado diferente (ou seja, ao passado somente se deve retornar quando se está protegido por alguma forma de seletividade, pois, não sendo assim, corremos o risco de recuperar a tradição). Além desses dois fatores, a psicanálise ganhava prestígio e se consolidava como método de análise social, tornando-se um importante aliado para interpretar as sucessivas e cambaleantes mudanças de foco da cena contemporânea.

Todo esse clima propício à descoberta de soluções sobre os destinos múltiplos da cultura vai sendo esvaziado em favor das reflexões pormenorizadas dos especialistas, que, a seguir, viriam preencher as páginas do suplemento. Assim, fruto de uma época que desconfia cada vez mais da noção de projeto, o Folhetim deixa de significar uma unidade orgânica que optava por oferecer a seu público, 
semanalmente, um caderno coeso sobre algum assunto vibrante, retirando das discussões culturais os conteúdos ligados, por exemplo, às questões mundanas da cidadania. Ao invés de se apresentar como uma formação coesa e uniforme, a partir de 1982, o Folhetim se traduz por uma sorte de fragmentos, ou melhor, como uma rapsódia cujas reverberações se misturam aos ruídos externos acelerando o seu desvanecimento.

\section{RESUMO}

A partir de um amplo mapeamento dos textos que circularam no Folhetim da Folha de São Paulo (1977-1989), o presente trabalho recorta e reagrupa a série de textos que abordavam os temas da psicanálise, da psiquiatria e da psicologia. Examinando as relaçōes entre essa série e os estudos literários, pretendo estabelecer alguns cruzamentos e realçar a interdependência que contribuiu para tornar a psicanálise uma das disciplinas mais atuantes junto ao campo literário. Além disso, procuro apresentar as polêmicas e as diversas orientações teóricas distintas que marcaram as múltiplas inserções dos temas (psicanalítico, psiquiátrico e psicológico) nas páginas do Folhetim.

Palavras-chave: Periodismo cultural, teoria da literatura, psicanálise, psicologia, psiquiatria.

\section{ABSTRACT}

From a broad collection of texts which were published in Folhetim of Folha de São Paulo, this study selects and reorganizes a series of texts focusing on psychoanalysis, psychiatry, and psychology. By examining the relationships between this series and literary studies, this study intends to determine their interweaving and highlight the interdependence that has contributed to the significance of psychoanalysis in the literary field. In addition, the study attempts to discuss the controversies and the various theoretical positions that have underscored the inclusion of the psychoanalytical, psychiatric, and psychological themes in Folhetim.

Key-words: Cultural studies, theory of literature, psychoanalysis, psychology, psychiatry. 


\section{REFERÊNCIAS}

CHECHINATO, D. Psicanálise e poder dominante. Folha de S. Paulo, 12 dez. 1982. p. 3.

EAGLETON, T. Teoria da literatura: uma introdução. Tradução: Waltensir Dutra. São Paulo: Martins Fontes, 1983.

RAVACHE, I. et al. Depoimentos. Folha de S. Paulo, 8 mar. 1981. p. 11.

A MULHER já não queima sutiã. Folha de S. Paulo, 30 set. 1979. p. 7.

KEHL, M. R. O mito do psicanalista. Folha de S. Paulo, 29 nov. 1981. p. 9.

LOPARIC, Z. Uma leitura filos6fica de Freud. Folha de S. Paulo, 31 ago. 1986. p. 7.

MENESES, A. B. Literatura e Psicanálise. Folha de S. Paulo, 11 dez. 1983. p. 4.

NABARRETE, S.; GOLDENBERG, J. P. O divã da periferia. Folha de S. Paulo, 11 mar. 1979. Entrevista, p. 8.

SILVA, A. Primeira carta aos andróginos. Folha de S. Paulo, 30 set. 1979. p. 9.

\section{ANEXO I}

Relação da série "psiquiatria", publicada entre 1977 e 1981.

D’AVILA, R. F; OLIEVENSTEIN, C. A droga. Psiquiatria, n. 30, p. 7-9, 14 ago. 1977.

ZIGGIATTI, L.; LAING, R. D. Ronald Laing: o impasse está criado. Psiquiatria, n. 72, p. 11-12, 4 jun. 1978.

ARNT, R. Que abram os manicômios. Psiquiatria, n. 92, p. 6-7, 22 out. 1978.

KLINTOWITZ, J.; BASAGLIA, F. Liberdade, remédio até para a loucura. Psiquiatria, n. 130, p. 8-9, 15 jul. 1979.

OLIVEIRA, E. Não há loucos na Pinel. Apenas brasileiros. Psiquiatria, n. 140, p. 14, 23 set. 1979. FORBES, J. F.; PRADA, C. O rico e o pobre, a mesma violência. Psiquiatria, n. 149, p. 8, 25 nov. 1979.

UMA palavra proibida na Pinel: viciado. Psiquiatria, p. 13, 3 ago. 1980.

WEREBI, S.; GOLDSTEJN, H. O que se esconde no uso de drogas. Psiquiatria, n. 185, p. 13, 3 ago. 1980.

MENDES, O. As desventuras da divina natureza das coisas. Psiquiatria, n. 217, p. 2, 8 mar. 1981. 
VASCONCELOS, M. A morte da saúde mental. Psiquiatria, n. 217, p. 7, 8 mar. 1981.

QUEM ganhou com os avanços da psiquiatria? Psiquiatria, n. 217, p. 9-11, 8 mar. 1981. Mesaredonda.

REIS, M. A.; VASCONCELOS, M. O tratamento fora do hospício enfrentando ventos e tempestades. Psiquiatria, n. 217, p. 8, 8 mar. 1981.

WAINBERG, D. A longa jornada até o manicômio. Psiquiatria, n. 256, 13 dez. 1981, p. 4.

\section{ANEXO II}

Grupo de textos que trazem a psicologia como foco das atençōes. Acompanha um breve resumo dos textos.

MOUTINHO, N. Mãe! n. 016, 8 maio. 1977, p. 17.

A reportagem pretende passar a limpo o papel da Mãe ao longo de toda a história da humanidade.

GAIARSA, J. A.; PENTEADO, R. Sem papas na língua, o incrível doutor mente. n. 061, 19 mar. 1978 , p. 3-6.

Nesta entrevista, José Ângelo Gaiarsa analisa as dificuldades, que a maioria das pessoas possui, em superar a "vontade". Para o entrevistado, a tensão gerada por esta situação pode levar a maioria destes indivíduos a se tornarem pessoas extremamente infelizes.

GOLDENBERG, J. P.; NABARRETE, S. $O$ divã da periferia. n. 112, 11 mar. 1979, p. 8-9.

Nesta entrevista, o psicólogo Jacob Pinheiro Goldenberg defende a idéia de se levar à periferia a psicoterapia através da Igreja, sindicatos e sociedades de bairro.

LEITE, R. M. C. O desenvolvimento sexual do adolescente. n. 174, 18 maio 1980, p. 8.

O depoimento enfatiza as mudanças que ocorrem no corpo humano durante a adolescência, $o$ problema da identidade e da sexualidade.

RIBEIRO, D.; BORGES, J. P. A psicologia faz sucesso na reabilitação individual. n. 217, 8 mar. 1981, p. 4.

A primeira reportagem consulta o conselheiro suplente do Conselho Regional de Psicologia, Lazslo Ávila, que fala da emancipação e do reconhecimento da psicologia como um instrumento de recuperação social do indivíduo. A segunda reportagem consulta o presidente da Associação Médica Brasileira, Pedro Kassab, que fala da necessidade de regulamentação da área para definir melhor as responsabilidades de cada profissional. A terceira reportagem (de J.P. Borges) aborda o tratamento desumano recebido pelo paciente mental, quando ele entra em uma instituição particular, cujo tratamento visaria apenas ao lucro.

KNOBEL, M. O adolescente, perdido entre mercadores de ilusões. n. 217, 8 mar. 1981 p. 6. 
O depoimento relaciona a exploração exercida pelo mercado de trabalho dos jovens à vulnerabilidade que eles estariam expostos (os mercadores de ilusões) quando o assunto é saúde mental.

FUKUI, L.; BRANDÄO, H.; BRUSCHINI, M. C. As forças ocultas do cotidiano. n. 251, 8 nov. 1981, p.11.

Nestas entrevistas, Lia Fukui e Maria Cristina Bruschini falam sobre o caráter autoritário da famı́lia, reflexo do autoritarismo da política nacional.

CUNHA, M. C. As paixōes e o crime. n. 264, 7 fev. 1982, p. 10.

A reportagem procura enfocar as origens psicológicas dos crimes passionais.

MACHADO, B. Uma busca epistemológica. n. 471, 16 fev. 1986, p. 3-4.

Segundo o texto, "se para a psicologia é fundamental a estrutura material do indivíduo, para a astrologia pouco importa que ele tenha um pai sádico ou uma mãe possessiva".

MASSI, M. Havana, o reatamento do diálogo entre psicanálise e marxismo. n. 501, 14 set. 1986, p. 8-11.

O texto analisa o encontro de psicólogos de vários países e orientações, ocorrido em Cuba, em 1986, que novamente colocou em pauta as convergências e as divergências entre a psicanálise e o marxismo.

\section{ANEXO III}

A seguir, apresento a relação dos textos que demonstram esta trajetória. Fazem parte dela os principais especialistas que colaboraram no suplemento: Chaim Samuel Katz, Fábio Hermann, Hélio Pelegrino, e Maria Rita Kehl. Entre as colaborações de Hélio Pelegrino e Maria Rita Kehl, fiz questão de manter os poemas $e$ as ficções, respectivamente, para demonstrar que as publicações não ficaram restritas aos temas psicanalíticos.

KATZ, C. S.

Um sofista entre nós. n. 254, 29 nov. 1981, p. 9.

O depoimento comenta a atuação do psicanalista Eduardo Mascarenhas: "Mascarenhas mostra aquilo que se quer segredo de uma classe (sic) e coloca a psicanálise como uma coisa a ser pensada e vivida".

Tristäo e Isolda. n. 267, 28 fev. 1982, p. 12.

O texto reflete sobre a 'postura' do espectador durante a execução da ópera de Richard Wagner.

Censura e psicanálise. n. 275, 25 abr. 1982, p. 3.

A partir dos conceitos de Freud, o texto analisa a censura "que se alastrou violentamente nos últimos 18 anos da vida urbana do Brasil, [e que] poderá obrigar a todos a sair da quietude e das 'grandes esperanças' dos últimos 6 anos". 
Formą̧ão psicanalítica e democracia, n. 280, 30 maio. 1982, p. 8.

De acordo com o texto, "a questão da democracia não está colocada apenas para as sociedades psicanalíticas de 'direita', mas também para os que se julgam de 'esquerda"."

Filosofia, saber e poder. n. 287, 18 jul. 1982, p. 9.

O texto reflete sobre uma dúvida: "será que o provável ensino de filosofia no curso secundário vai destacar o saber múltiplo de Parmênides, Protágora ou Zenão de Eléia?"

Ordem familiar e limites da loucura. n. 333, 5 jun. 1983, p. 10-11.

De acordo com o texto, "no Brasil, cria-se uma unanimidade entre a direita e uma certa esquerda quanto aos doentes mentais. Os primeiros querem devolvê-los a suas famílias, porque estas sendo as 'células mãe' da sociedade, deverão corrigi-los. Os outros buscam acabar com a noção de doença mental - se ela não existe, eles serão refamiliarizados, recobrando seu bem-estar".

Foucault e a loucura. n. 397, 26 ago. 1984, p. 4-5.

A partir da "História da loucura", de Foucault, o texto procura rastrear o modo pelo qual "a razão ocidental excluiu cruelmente o louco e despojou-o de seus direitos de cidadania".

\section{HERMANN, F.}

A psicanálise encontra o seu lugar, o cotidiano. n. 226, 17 maio 1981, p. 10-11.

O texto reflete sobre a ampliação da ação da psicanálise na sociedade e o seu lugar no cotidiano.

Os atrativos do vazio. n. 254, 29 nov. 1981, p. 4.

O texto reflete sobre a ligação que se faz entre a psicanálise e o poder. "Por que apontá-la só neste contexto, se ela está em toda a parte?", pergunta o texto.

Aéreos, subterrâneos: nossos filósofos chegam à psicanálise. n. 428, 31 mar. 1985, p. 2-3.

O texto procura avaliar as profundas relações entre a filosofia brasileira e o pensamento freudiano, destacando a revisão da obra de Freud à luz da filosofia contemporânea.

A dor de cotovelo no divã. n. 466, 12 jan. 1986, p.7-9.

"Em entrevista ao Folhetim, Fábio Hermann discute alguns dos tópicos de seu livro, como a possibilidade de uma psicanálise à brasileira, a noção do real, na teoria e no cotidiano, e os casos, agora clínicos, do teimoso, do saudoso, e daquele dono de uma tremenda dor-de-cotovelo".

Psicanálise em São Paulo. n. 488, 15 jun. 1986, p. 8-9.

Refletindo sobre a função de psicanalista, o autor sentencia: "o nosso é um ofício absurdo impossível não é, visto que se exerce. Lidamos com o mundo pelo avesso, é verdade. Mais uma razão para sensatez". 


\section{PELEGRINO, $\mathrm{H}$.}

A sociedade psiquiátrica e a expulsão dos demônios. n. 217, 8 mar. 1981, p. 3.

"O psicanalista - expulso da Sociedade Psicanalítica do Rio de Janeiro - conta, neste artigo, porque discorda da entidade, que considera preocupada em manter 'gordos privilégios"".

Poemas - O galo/ Fleshback/ Os suicidas/ Piquenique/ O bêbado Segismundo/ Antônia dorme/

As asas pensadas/ Passarão. n. 295, 12, set., 1982, p.12.

Formação ou deformação. n. 324, 3 abr. 1983, p. 3-5.

Segundo o texto, "o didata investido pela instituição, revestido pelas exigências burocráticas que esta lhe faz, vai levar para o espaço analítico um discurso pronto, prévio, fechado e opaco, que não se coaduna com o lugar do analista e com a função simbólica que lhe é reservada".

Poema - Copacabana à tarde. n. 340, 24 jul. 1983, p. 12.

Pacto edipico e pacto social. n. 347, 11 set. 1983, p. 9-11.

«A ruptura com o pacto social, em virtude de sociopatia grave - como é o caso brasileiro - pode implicar a ruptura ao nível do (sic) inconsciente, com o pacto edípico. Não nos esqueçamos que o pai é o primeiro e fundamental representante da lei da cultura. Se ocorre por retroação uma tal ruptura, fica destruído no mundo interno, o significante paterno, o nome-do-pai, e em consequiência o lugar da lei".

Psicanálise da criminalidade brasileira. n. 403, 7 out. 1984, p. 6-8.

De acordo com o texto, "a criminalidade é uma forma enlouquecida de protesto, e é preciso que a indignação e a inconformidade do povo possam formular-se em termos políticos, de modo a tornála desnecessária e, portanto, verdadeiramente ultrapassável".

Poema - As coisas dadas. n. 416, 6 jan. 1985, p. 2.

As instituições psicanaliticas no divã n. 434*, 19 maio.,1985, p. 6-9

(colaboram: BARRETO, C.; PELEGRINO, H. e MAROJA, P.).

De acordo com o texto, "por trás da Sociedade Psicanalítica do Rio de Janeiro e de seu discurso totalitário ocultam-se mecanismos de recalque, pulsōes e compulsões. $O$ analista formado por ela é vítima desse esconde-esconde".

\section{KEHL, M. R.}

Sexo, a preços módicos. n. 224, 3 maio. 1981, p. 8.

O texto reflete sobre o mercado do sexo, "a sexologia", no contexto da indústria cultural, como ilusão de satisfação sexual.

O sacrifício dos deuses. n. 227, 24 maio. 1981, p.7.

O texto analisa o comportamento dos meios de comunicação que transformaram os atentados terroristas contra o Papa, John Lennon e Ronald Reagan, em show. 
Três respostas d̀s senhoras de Santana. n. 230, 14 jun. 1981, p. 3.

O depoimento é uma resposta, em tom de severa crítica, ao pedido de maior rigor da censura à televisão feito pelas "Senhoras de Santana".

As modas do colonizado. n. 233, 5 jul. 1981, p. 13.

O texto avalia que "a importação de modismos passou da elitização para a democratização dos costumes".

Fiç̧ão - O casamento (i)real. n. 238, 9 ago., 1981, p. 16.

Elas por elas. n. 240, 23 ago. 1981, p. 10.

O texto reflete sobre a expansão do mercado representado pela ascensão econômica e social da mulher.

O rei morreu. Viva o rei. n. 24l, 30 ago. 1981, p. 12.

Fazendo diversas ressalvas, o depoimento presta homenagem (logo depois da morte) ao "gênio" Glauber Rocha.

O proprietário do pensamento. n. 245,27 set. 1981, p. 10.

O texto entra na polêmica entre Marilena Chaú e José Guilherme Merquior e introduz o questionamento sobre a possibilidade de alguém ter propriedade de uma idéia.

Viver e conviver. n. 251,8 nov. 1981 , p. 12.

Segundo o texto, "quando a objetividade compulsória substitui a riqueza das trocas entre subjetividades, caminha-se para o autoritarismo que é a morte em vida".

$O$ mito da psicanalista. n. 254, 29 nov. 1981, p. 9.

Segundo o texto, "só a socialização da práxis psicanalítica pode dessacralizar a 'ciência-mito' de nossos dias".

Polftica da desilusão. n. 259, 3 jan. 1982, p. 11.

O depoimento elabora o perfil da sucessão política em São Paulo, lamentando não ter no PT um nome forte para concorrer com Montoro e Maluf e, dos males o menor, acaba por apoiar Montoro.

As raizes cotidianas da corrup̧̧ão. $\mathrm{n}$. 264, 7 fev. 1982, p. 9.

Segundo o texto, "a corrupção doméstica forma o pano de fundo social favorável a todas as grandes corrupçōes, a todas as grandes traições que escandalizam a nossa má consciência".

Fição - Carnaval todo desejo. n. 266, 21 fev. 1982, p.12

Abaixo os clichês! n. 267, 28 fev. 1982, p. 4.

O depoimento enfatiza que a utilização do rótulo "marginal" pode ser demasiado pretensioso.

Antidepressivos para desesperançados. n. 471, 16 fev. 1986, p.5.

$\mathrm{O}$ texto discute alguns dos efeitos apaziguadores que as novelas transmitem aos espectadores. De acordo com o texto, "em Roque Santeiro, só as prostitutas e os padres fazem o espectadores felizes; assim, o pálido herói ora se abriga na igreja, ora na casa da viúva". 


\section{ANEXO IV}

A seguir, relaciono os debates que trataram diretamente da exclusão das mulheres, dos negros, dos homossexuais e dos índios.

A questão da mulher:

E o poder da mulher? n. 059, 5, mar., 1978, p.3-6.

Neste debate, coordenadas pelos jornalistas Irede Cardoso, Nelson Merlin e Licínio de Azevedo, Ruth Escobar (atriz), Silvia Pimentel (professora), Nilce Trajan (publicitária), Maria Inês Castilho (jornalista), Marlene Crespo (desenhista) e Maria Amélia Teles falam de suas experiências (participação e conquistas) pessoais em áreas diversas da sociedade brasileira.

Educação sexual nas escolas n. 094, 5, nov., 1978, p.10-11.

O Folhetim reúne João Alfredo Meireles (psicólogo), Waldenyr Caldas (sociólogo), Atílio del Greco (vendedor autônomo), a esposa Maria de Loudes Fraga Lopes e suas três filhas, Raquel Moreno (jornalista), Cibele de Lima (estudante de sociologia) e a sexóloga Maria Helena Matarazzo para discutirem a questão da educação sexual nas escolas.

Mesa-redonda: a mulher já não queima sutiã. n. 141, 30, set., 1979, p.7-8.

Coordenadas por Cecília Prada, as antropólogas Mariza Corrêa e Verena Stolcke e a socióloga Rosalina Santa Cruz Leite discutem a mudança de comportamento da mulher na década de 70.

O que elas querem? A metade de tudo. n. 143, 14, out., 1979, p.3.

Coordenadas por Maria Carneiro da Cunha, Silvia Pimentel, Anésia Pacheco Chaves, Marta Suplicy e Maria Malta Campos discutem que tipo de liberdade e quais as conquistas que mais interessam às mulheres.

A mulher pediu a palavra. n. 143,14 , out., 1979, p.7-9.

Coordenadas por Irede Cardoso, Irma Passoni (deputada), Angela Náder (empresária), Ione Cirilo (jornalista), D.Hilda (sindicalista), Marly Cardoni (USP) e Regina Duarte discutem sobre o tamanho da fatia da política que deve ser reservada às mulheres brasileiras.

O que há de novo nesses partidos. n. 162, 24, fev., 1980, p.7-12.

Nesta mesa-redonda, coordenada pelo professor Tércio Sampaio Ferraz Jr., alguns convidados (Jarbas Passarinho - PDS, Almino Afonso - PMDB, Chico de Oliveira, Fábio Munhoz e José Álvaro Moisés - PT, o prefeito de Osasco Guaçu Piteri, Orlando Miranda - PTB, Cláudio Lembo e Aluísio Alves PP) discutem os novos rumos da política nacional, agora, com liberdade de organização partidária. No final dos depoimentos e do debate, há uma nota sobre a participação da FENEMÊ(Frente Nacional das Mulheres), que pretende reivindicar dos partidos maior participação das mulheres.

E a liberdade sexual, vai bem? n. 165, 16, mar., 1980, p.8-12.

Coordenados pelo jornalista Oswaldo Mendes, a psicanalista Betty Milan, o antropólogo Peter Fry, a professora Marilena Chauí, o psiquiatra Flávio Gikovate, o psicólogo Angel Pino e a professora Sílvia Pimentel discutem os principais objetos e objetivos dos desejos dos brasileiros. 
Casamento e maternidade: o que mudou? (mesa-redonda). n. 216, 15, mar., 1981, p.10-15.

Coordenados por Marilena Chauí, Carmem Barroso (psicóloga), Heleith Saffiotti (socióloga), Irede Cardoso (jornalista), Olgária Férez (filósofa) e Lígia Fagundes Telles (escritora) discutem sobre as novas relações da mulher com o casamento e com a maternidade.

As lutas pela cidadania têm dois séculos de atraso. n. 219, 29, mar., 1981, p.13-16.

Coordenados por Dalmo Dallari, Marilena Chaú, Olívio Dutra, Plínio de Arruda Sampaio, Paulo Francini e Rubens Vaz da Costa discutiram a questão da cidadania e o cumprimento das leis no Brasil.

A democracia passa pela discussão do pluralismo cultural. n. 220, 5, abr., 1981, p.6-9.

Sob a coordenação de Roberto Schwartz (USP), Gilberto Velho (antropólogo), Leda Alves (UFPE), Mário Schenberg (crítico de arte) e Cacaso (poeta) discutiram sobre a questão da identidade cultural brasileira.

O aborto em questão. n. 223, 26, abr., 1981, p.6-8.

Coordenados pelo jornalista Henrique Nunes, D. Luciano Mendes de Almeida (da CNBB) e Carmem Barroso (da Frente de Mulheres Feministas) discutem sobre a questão do aborto.

Feminismo e antropologia - A mulher e a ideologia. n. 227, 24, maio., 1981, p.8-11.

Coordenada por Mariza Correia, Bruna Franchetto, Maria Luiza Heilborn e Maria Laura Cavalcanti refletem sobre a polêmica discussão a respeito da existência ou não de uma identidade feminista universal.

Mulher negra, essa quilombola. n. 253, 22, nov., 1981, p.4.

GONZALES, Lélia. A reportagem informa que "a situação da mulher negra hoje não é muito diferente de seu passado de escravidão".

A mulher, alvo preferencial de violência (mesa-redonda). n. 256, 13, dez., 1981, p.6-8.

Coordenados por Dalmo Dallari, Rachel Moreno, Maria Carneiro da Cunha, Aparecida Kopcak e Helena de Grammont discutem os efeitos de uma sociedade que exerce, de diversas formas, a violência como forma de conservar a dominação.

A questão do homossexualismo:

Gay, com orgulho. n. 141, 30, set., 1979, p.8-9.

MORAIS, Antonio Carlos. Esta reportagem procura enfocar os problemas decorrentes do comportamento homossexual e a crescente consolidação do poder gay.

Do gueto para o debate público. n. 260, 10, jan., 1982, p.6-8.

Sob a coordenação de Irede Cardoso, o Folhetim reúne Flávio Gikovate (psicanalista), João Batista Breda(deputado), João Silvério Trevisan e Darci Penteado (ambos do jornal Lampião), que discutem os direitos das minorias em uma sociedade que mal respeita a maioria.

O corpo, esse desconhecido. n. 261, 17, jan., 1982, p.6-8. 
FERREIRA, Antônio Carlos. O Folhetim transcreve um resumo do debate realizado em 31 de outubro de 1981 em Florianópolis, dentro do X Congresso Brasileiro de Comunicação Social. Trata-se de um debate sobre as políticas do corpo, com a presença de Femando Gabeira, do sociólogo Manuel Berlinck, da professora Maria Helena Weber, do sociólogo e antropólogo Renato Ortiz, do escritor Paulo Schilling, sob a coordenaçāo da psicóloga Ana Verônica Mautner.

A questão dos negros:

Quilombismo. n. 138, 9, set., 1979, p.7-9.

Coordenados pelo jornalista Antonio Zago, Hamilton B. Cardoso e Mima Grzich debatem com o líder negro Abdias do Nascimento os princípios e os propósitos do quilombismo (movimento de conscientização política e cultural).

O terceiro tom da liberdade. n. 141, 30, set., 1979, p.2.

ALBUQUERQUE, José Augusto Guilhon de. O editorial destaca a importância de um número destinado a discutir o comportamento da década de 70 porque ela combinou, às vezes de maneira explosiva, a revolta dos jovens $\mathrm{e}$ as minorias sociais.

Mesa-redonda. Comunidades indígenas. n. 170, 20, abr., 1980, p.7-10.

Coordenados pelo professor Carlos Guilherme Mota, Audálio Dantas (jornalista e deputado), Lux Vidal (antropóloga da USP), Carmem Junqueira (antropóloga da PUC-SP), Tenente Brigadeiro João Camarão Telles Ribeiro, Cláudia Andujar (da Funai), Modesto da Silveira (deputado-RJ), Dom Tomás Balduíno (bispo de Goiás), Olympio Serra (ex-Funai) e Aracy Lopes da Silva (antropóloga da USP) discutem a sobrevivência das comunidades indígenas no Brasil.

Mesa-redonda. Democracia racial, o mito e o desejo. n. 177, 8, jun., 1980, p.7-11.

Coordenados por José Guilhon de Albuquerque, o historiador Boris Fausto, a cineasta Tizuka Yamazaki, a antropóloga Manuela Carneiro da Cunha, o sociólogo Clóvis Moura, o professor Joel Rufino dos Santos, Nilton Barbosa (do Movimento Negro Unificado), o escritor Maurício Segall e o advogado Esmeraldo Tarquínio discutem o mito (ou o desejo) de que vivemos em uma democracia racial.

Mesa-redonda. E o oprimido que se organiza frente ao opressor. n. 220, 5, abr., 1981, p.10-12.

Folhetim. Sob coordenação de José Carlos Dias (advogado), Joel Rufino dos Santos (historiador), Carmem Junqueira (antropóloga), Jacqueline Pitanguy (sociologa), Paulo Ruy de Oliveira (vereador SP) e Peter Fry (antropólogo) discutiram sobre uma possível equação da questão das minorias sociais.

A cor da pele. n. 240,23 , agos., 1981, p.12.

SANTIAGO, Silviano. O texto analisa a poesia de Adão Ventura que, segundo o ensaio, reavalia a condição social do negro.

O hitlerismo revivido. n. 243,13 , set., 1981, p.12

CASTRO, Moacir Werneck de. $O$ texto elabora o quadro político que gerou e continua fortalecendo o regime de segregação racial na África do Sul.

Volta à terra da memória. n. 253, 22, nov., 1981 p.9 
NASCIMENTO, Beatriz; GERBER, Raquel. Nesta entrevista, Beatriz Nascimento fala sobre a preservação da cultura negra que era mantida dentro dos Quilombos.

Cultura negra comunicação. n. 253, 22, nov., 1981, p.9.

VASCONCELOS, Mariângela. A reportagem enfoca o enraizamento das influências dos povos africanos em nossos costumes.

A luta continua. n. 253, 22, nov., 1981, p.8.

NASCIMENTO, Abdias do; CARDOSO, Hamilton Bernardes. Nesta entrevista, Abdias do Nascimento fala sobre a necessidade de engajamento da comunidade negra na luta por melhorias sociais.

A consciência negra e a comunidade. n. 253, 22, nov., 1981, p.4-5.

CARDOSO, Hamilton Bemardes. A reportagem consulta José Adão de Oliveira, do Movimento Negro Unificado, que fala sobre a necessidade de um projeto identificado com as necessidades do negros brasileiros.

A esperança branca. n. 270, 21, mar., 1982, p.5.

GONZÁLES, Manuel Pedro. A reportagem enfoca a necessidade de a sociedade reconhecer o seu proprio racismo.

Mesa-redonda. Os negros e os partidos. n. 282, 13, jun., 1982, p.10-11.

Coordenados por João Batista Pereira, Teodosina Ribeiro (PDS), Abdias do Nascimento (PDT), Esmeraldo Tarquinio (PMDB), Milton Barbosa (PT) e Antonio Sabino (PTB) discutem sobre o problema dos negros na sociedade brasileira.

A questão dos índios:

A sociedade branca é uma capa, que o ́ndio usa para sobreviver. n. 224, 3, maio., 1981, p.5.

BORGES, José Paulo. Neste depoimento, Marcos Terena, "fundador da União das Nações Indfgenas, defende a preservação da identidade do índio".

Direitos humanos, a hora do índio. n. 227, 24, maio., 1981, p.3-4.

CUNHA, Maria (Manuela) Carneiro da. O depoimento da representante da Comissão Pró-índio enfatiza a necessidade de se restabelecerem os direitos dos índios brasileiros.

A tribo chega à "civilização". n. 227, 24, maio., 1981, p.5-6.

LUPPI, Carlos Alberto. A reportagem consulta o índio tukano Álvaro Fernandes, que fala sobre a destribalização promovida pelos padres salesianos e a construção da Perimetral Norte.

A panela vazia da civilização. n. 232, 28, jun., 1981, p.6.

SCHWADE, Egydwo. O depoimento enfatiza a situação caótica dos últimos seiscentos índios Waimiri e Atroari, que estão ameaçados pela construção de uma usina hidroelétrica. racismo.

Mesa-redonda. Os negros e os partidos. n. 282, 13 jun. 1982, p. 10-11.

Coordenados por João Batista Pereira, Teodosina Ribeiro (PDS), Abdias do Nascimento (PDT), 
Esmeraldo Tarquinio (PMDB), Milton Barbosa (PT) e Antonio Sabino (PTB) discutem sobre o problema dos negros na sociedade brasileira.

A questão dos índios:

A sociedade branca é uma capa, que o índio usa para sobreviver. n. 224, 3 mai. 1981, p. 5.

BORGES, J. Neste depoimento, Marcos Terena, "fundador da União das Nações Indígenas, defende a preservação da identidade do índio".

Direitos humanos, a hora do índio. n. 227, 24 mai. 1981, p. 3-4.

CUNHA, Maria (Manuela) Carneiro da. O depoimento da representante da Comissão Pró-índio enfatiza a necessidade de se restabelecerem os direitos dos índios brasileiros.

A tribo chega à "civilização". n. 227, 24 mai. 1981, p. 5-6.

LUPPI, C. A. A reportagem consulta o indio tukano Álvaro Fernandes, que fala sobre a destribalização promovida pelos padres salesianos e a construção da Perimetral Norte.

A panela vazia da civilização. n. 232,28 jun. 1981, p. 6.

SCHWADE, E. O depoimento enfatiza a situação caótica dos últimos seiscentos índios Waimiri e Atroari, que estão ameaçados pela construção de uma usina hidroelétrica. 